\title{
THERMAL CONDUCTIVITY OF INSULATION BRICK DEVELOPED FROM SAWDUST AND SELECTED UGANDA CLAYS
}

\author{
Edward. Bwayo ${ }^{1}$, S. K. Obwoya ${ }^{2}$ \\ ${ }^{1}$ Department of Physics, Kyambogo University, P.O. Box 1, Kyambogo, Kampala, Uganda \\ ${ }^{2}$ Department of Physics, Kyambogo University, P.O. Box 1, Kyambogo, Kampala, Uganda
}

\begin{abstract}
This paper presents a study on the effect of particle size of a mixture of kaolin and ball clay incorporated with wood sawdust on thermal conductivity of fired bricks. Powders of kaolin, ball clay and saw dust were mixed in certain proportions then compacted to high pressure of $50 \mathrm{MPa}$ before being fired to a temperature of $950{ }^{\circ} \mathrm{C}$. The results show that thermal conductivity increases with decrease in particle size of kaolin and ball clay, but decreases with increase in particle size of sawdust.
\end{abstract}

Keywords: Thermal conductivity; sawdust; chemical composition; thermal insulator; porosity; ceramic material. $* * *$

\section{INTRODUCTION}

Bricks are construction materials which have been used since ancient times in Uganda, (Cultrone \& Torre, 2005). The use of bricks in construction is to setup strong structures and in addition shield the interior from heat in the environment. Thermal conductivity of a building material is an important parameter in calculating and designing the energy consumption of a building. Thus, thermal insulation properties of building materials such as traditional clay bricks and tiles are of paramount importance, (Turgut \& Yesilata, 2008). The locally made construction bricks in Uganda generally have high bulky density and therefore easily transmit heat energy from the surroundings into the building structures. The solar radiation from the sun is very strong and all is absorbed by the walls, veranda or some may pass directly into the structure through the windows, thus increasing the room temperature, (Gregory, 2007; AGO, 2004). Consequently, this tends to increase the cost of energy for the local people since they would require cooling systems.

Uganda is well endowed with a vast amount of mineral depositions in different parts of the country. There are large deposits of ball clay from Mukono and the swampy areas around the shores of Lake Vitoria, flint from Mutaka, and kaolin from Namasera and Mutaka, feldsper from Lunya,
Karamoja and Mutaka. See Fig.1 for locations of these places. These deposits can be used in the production of different domestic and industrial ceramic products like thermal insulating bricks, (Kirabira 2005). This paper therefore presents experimental results of the insulation properties of porcelain bricks produced from fired mixtures of kaolin, ball clay, and sawdust of compositions as shown in Table 2, that enhance low thermal conductivity.

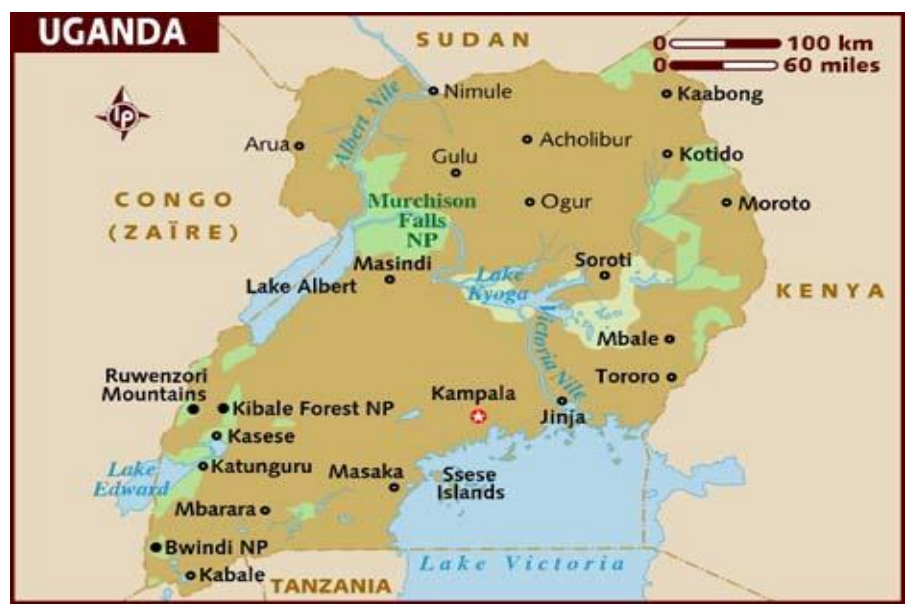

Fig 1: Map of Uganda showing locations of the raw materials

Table 1: Chemical composition of fired samples

\begin{tabular}{|l|l|l|l|l|l|l|l|l|l|l|}
\hline Compound & $\mathrm{SiO}_{2}$ & $\mathrm{Al}_{2} \mathrm{O}_{3}$ & $\mathrm{Fe}_{2} \mathrm{O}_{3}$ & $\mathrm{CaO}$ & $\mathrm{TiO}_{2}$ & $\mathrm{Na}_{2} \mathrm{O}$ & $\mathrm{MgO}$ & $\mathrm{K}_{2} \mathrm{O}$ & $\mathrm{MnO}_{2}$ & $\mathrm{P}_{2} \mathrm{O}_{5}$ \\
\hline Weight (\%) & 67.98 & 22.29 & 1.87 & 1.15 & 0.48 & 2.04 & 1.04 & 2.54 & 0.05 & 0.57 \\
\hline
\end{tabular}

\section{EXPERIMENTAL PROCEDURES}

\subsection{Materials Processing}

The raw materials of clays were prepared into powders through standard procedures. The sieving of clay and sawdust was done using standard test sieves whereby, the test sieves were stuck together on the mechanical test sieve shaker with the sieve of largest aperture at the top followed by those of small aperture below, down to smallest size at the bottom. Powders of kaolin and ball clay of particle size ranges of $0-45 \mu \mathrm{m}, 45-53 \mu \mathrm{m}, 53-63 \mu \mathrm{m}, 63-90 \mu \mathrm{m}, 90-$ $125 \mu \mathrm{m}$ and $125-154 \mu \mathrm{m}$ were prepared. Dry powders of sawdust of particle size ranges $0-125 \mu \mathrm{m}, 125-154 \mu \mathrm{m}, 154-$ $180 \mu \mathrm{m}, 180-355 \mu \mathrm{m}$ and $355-425 \mu \mathrm{m}$ were also prepared. 
Mvule timber is a hard wood and when sawdust from it is mixed with clay, the bricks formed have uniform pores and no bloating or expansion after firing, (Katherine et. al 2002).

The study had two parts comprising of batch formulations $A_{1}-A_{5}$, which had kaolin and ball clay of the same particle size ranges, mixed with sawdust of three different particle size ranges in the ratios 9:7:4 by weight as shown in Table 2. The mixtures of these powders were compacted into rectangular specimens with dimensions of $10.51 \mathrm{~cm} \mathrm{x}$ $5.25 \mathrm{~cm} \times 1.98 \mathrm{~cm}$ to pressures of $50 \mathrm{MPa}$. The test samples were fired to $950^{\circ} \mathrm{C}$ in an electric furnace in two stages. In the first stage they were fired at a heating rate of $2.33{ }^{\circ} \mathrm{C}$ $\min ^{-1}$ to $110^{\circ} \mathrm{C}$ and this temperature was maintained for four hours in order to drive water in them off. In the second stage, the samples were fired at a rate of $6^{\circ} \mathrm{Cmin}^{-1}$ to $950{ }^{\circ} \mathrm{C}$ $\min ^{-1}$. At this temperature, the holding time was one hour before the furnace was switched off to allow the samples cool naturally to room temperature. Part two of the study had batch formulations $B_{1}-B_{5}$, which had each of the particle size ranges $0-125 \mu \mathrm{m}, 125-154 \mu \mathrm{m}, 154-180 \mu \mathrm{m}, 180$ $355 \mu \mathrm{m}, 355-425 \mu \mathrm{m}$ of sawdust mixed with a combination of kaolin and ball clay of the same particle size ranges in the ratio 4:9:7 as shown in Table 2, before compacting them to pressures of $50 \mathrm{MPa}$ into rectangular specimens and firing them.

Table 2: Batch formulation of the samples

\begin{tabular}{|l|l|l|l|l|}
\hline \multicolumn{4}{|l|}{ Particle size $(\mu \mathrm{m})$} \\
\hline Sample & $\begin{array}{l}\text { Kaolin(90g)+ball } \\
\text { clay(70g) }\end{array}$ & \multicolumn{4}{l|}{ Sawdust addition, $(40 \mathrm{~g})$} \\
\hline A-1 & $90-125$ & $0-125$ & $125-154$ & $154-180$ \\
\hline A-2 & $63-90$ & $0-125$ & $125-154$ & $154-180$ \\
\hline A-3 & $53-63$ & $0-125$ & $125-154$ & $154-180$ \\
\hline A-4 & $45-53$ & $0-125$ & $125-154$ & $154-180$ \\
\hline A-5 & $0-45$ & $0-125$ & $125-154$ & $154-180$ \\
\hline & \multicolumn{4}{|l|}{ Kaolin $(90 \mathrm{~g})+$ ball clay (70g) } \\
& Sawdust (40g) & $63-90$ & $90-125$ & $125-154$ \\
\hline B-1 & $0-125$ & $63-90$ & $90-125$ & $125-154$ \\
\hline B-2 & $125-154$ & $63-90$ & $90-125$ & $125-154$ \\
\hline B-3 & $154-180$ & $63-90$ & $90-125$ & $125-154$ \\
\hline B-4 & $180-355$ & $63-90$ & $90-125$ & $125-154$ \\
\hline B-5 & $355-425$ & \multicolumn{4}{l}{} \\
\hline
\end{tabular}

\subsection{Thermal Conductivity Test}

Thermal conductivity was measured by the Quick Thermal Conductivity Meter (QTM-500) with sensor probe (PD-11) which uses transient technique (non-steady state) to study the heat conduction of samples. The results for thermal conductivities of the samples are displayed in Fig. 2; Fig. 3.

\subsection{Chemical Analysis of Fired Samples}

The chemical composition of the fired specimen was determined by the X-ray fluorescence (XRF), spectrometer, model $X^{\prime}$ Unique 1l. Chemical composition (Table 1) of the fired samples was done to establish conformity to composition of light weight thermal insulation clay bricks.

\section{RESULTS AND DISCUSSIONS}

\subsection{Effect of Particle Size of a Mixture of Kaolin} and Ball Clay with Sawdust of Different Particle

\section{Sizes}

The results (Fig.1) show that thermal conductivity increases with decrease in particle size of kaolin and ball clay at fixed particle size of sawdust addition. Large particles of clay create large pores due to poor filling of the voids. These voids contain air after firing which insulate thermal flow. Small particle sizes have small inter particle distance hence produce small pores, (Kadir, 2010; Viruthagiri et al. 2013). This is because the decrease in particle size increases particle content per unit volume which decreases the average inter-particle distance of the clay matrix. Thus, fine grained materials have much greater thermal conductivity than one with a coarser open texture. Secondly small particles aggregate due to high surface energy. This results into close parking of particles due to crashing of small pores. This leads to increase in thermal conductivity of the samples as particle size of clay decreases, (Zhang et al. 2011; Viruthagiri et al. 2013). Though thermal conductivity is high for small particle size of kaolin and ball clay, addition of sawdust of large particle size further decreases the thermal conductivity. The thermal conductivity of bricks is mainly related to their bulk density, so that increasing the thermal insulating properties implies the production of materials with a higher porosity that yields low density. According to Nonthaphong (2013), the effectiveness of a ceramic material depends critically on its crystal structure and chemical composition of their essential constituents and the amount of accessory minerals present, (Kingery 1976).

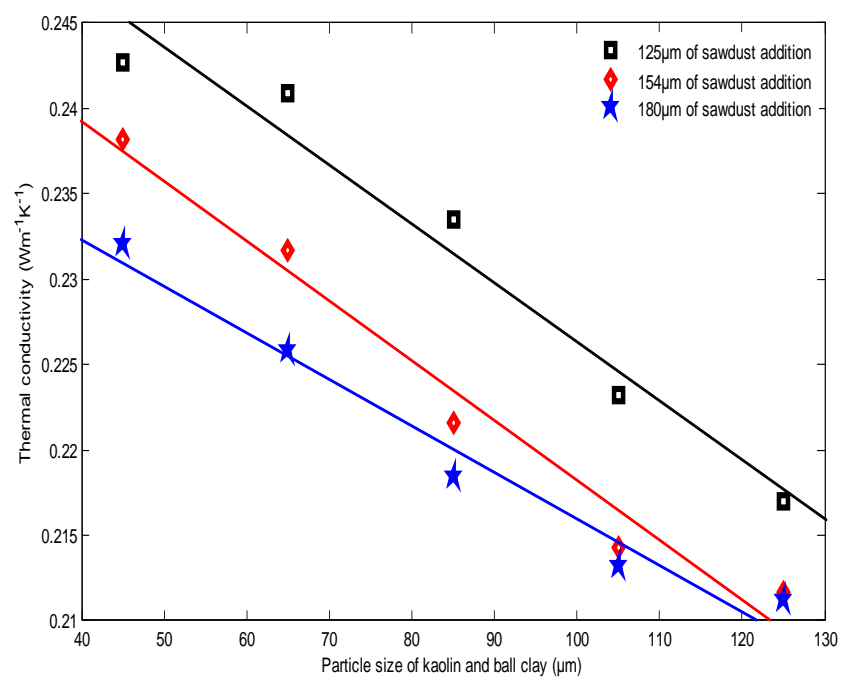

Fig 2: Effect of particle size of kaolin and ball clay on thermal conductivity with different particle size of sawdust.

The results (Fig. 2) show that thermal conductivity of the samples decreases with increase in particle size of sawdust incorporated into the clay combination of a particular particle size. Addition of sawdust to larger particle size of a mixture of kaolin and ball clay further decreases the thermal 
conductivity. This trend is in close in agreement with the findings of (Hanifi et al. 2007; Saiah et al. 2010; Ling 2010; Ayugi 2011). Related to this, Olufemi \& Aramide, (2012), established that thermal conductivity of a ceramic material is affected by chemical composition, porosity, particle size distribution of clay materials and particle size of combustible organic matter. During firing, sawdust burns out creating empty spaces or pores. The empty spaces or voids created after combustion of sawdust insulate the thermal flow. Increase in particle size of sawdust produces bigger pores in the sample when sawdust burns out. The air trapped in the pore acts as an insulator, (Abiriga \& Obwoya, 2014; Benjamin et al. 2006).

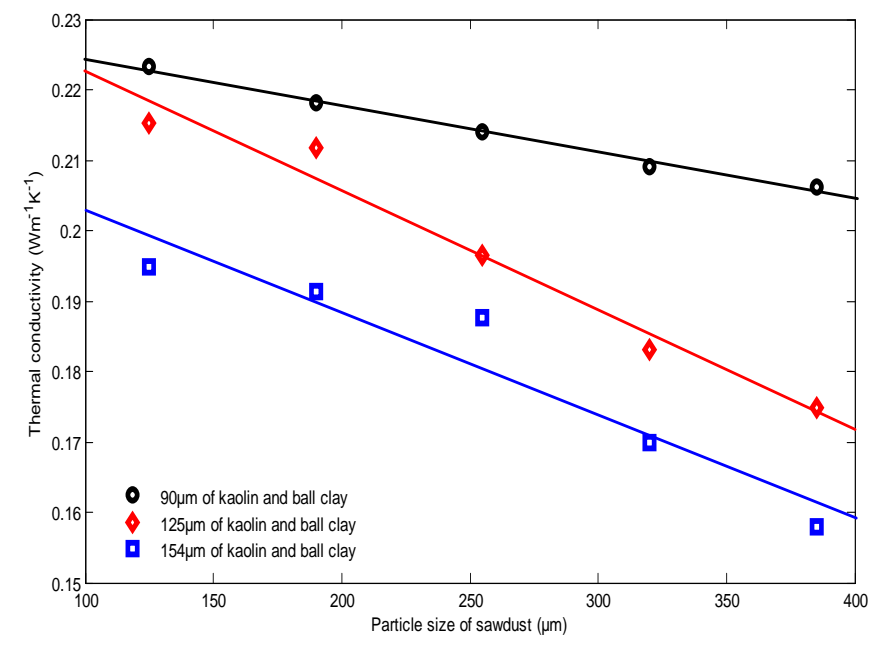

Fig 3: Effect of particle size of sawdust addition to fixed particle size of kaolin and ballclay

\subsection{Effect of Particle Size on Density}

The density of the samples increases with decreasing particle size of the mixture of kaolin and ball clay at fixed particle size of sawdust, (Fig. 4). This is because smaller particle sizes have more contact points that allow for more cohesion and lubrication of kaolin by ball clays. Multiple particle sizes in a ceramic body increase packing of particles and produces high density body because finer grains go into the inter-particle voids of the coarser particles and thus increase the packing density, (Zhang et al. 2011). This study also shows that there is further decrease in density with increase in particle size of sawdust addition at fixed particle size of kaolin and ball clay.

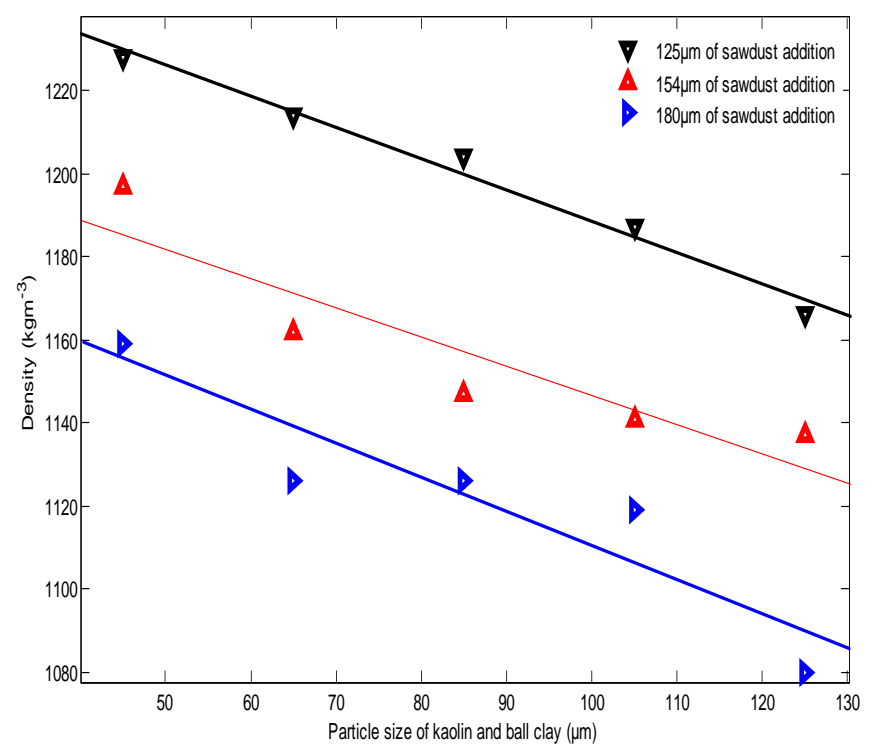

Fig 4: Variation of density with particle size of kaolin and ball clay for different particle size of sawdust

In Fig 5, density of the samples decreases with increase in particle size of sawdust for fixed particle size of kaolin and ball clay. This is because small pores created by small particle size of sawdust tending to be crushed by clay minerals as a result of formation of contact areas intergranular, while large pores will remain in the clay matrix, (Hanifi et al. 2007), during firing and maturing. Addition of sawdust to a higher particle size of kaolin and ball clay further decreases the density.

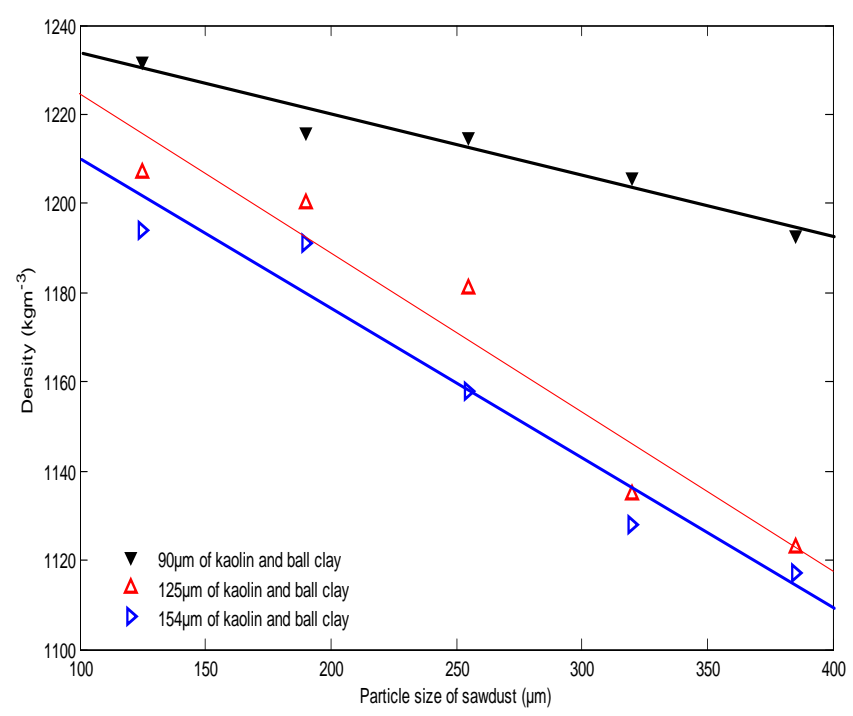

Fig 5: Variation of density with particle size of sawdust at different particle size of kaolin and ball clay

\subsection{Chemical Composition}

The samples used for the study had $\mathrm{SiO}_{2}$ (67.9\%) which complies with percentage compositions of low density insulation bricks. The composition of $\mathrm{Al}_{2} \mathrm{O}_{3}(22.3 \%)$, is 
slightly lower than that recommended by UNEP (2006) for light weight insulation clay bricks. However, the chemical composition of alumina can be improved either by beneficiating the raw materials (kaolin and ball clay) or by increasing the percentage composition of kaolin in the samples. As a whole, the samples have low heat conduction and are therefore suitable for use as thermal insulators.

\section{CONCLUSIONS}

The results of the study show that all the samples analyzed are good thermal insulators and that thermal conductivity is directly affected by particle size of a combination of kaolin and ball clay minerals as well as particle size of sawdust addition. Thus from the overall experimental analysis carried out, it was observed that:

1. Thermal conductivity increases with decrease in particle size of a mixture of kaolin and ball clay at fixed particle size of sawdust addition.

2. Addition of sawdust of larger particle size decreases thermal conductivity even at very small particle size of kaolin and ball clay.

3. Thermal conductivity decreases with increase in particle size of sawdust addition to a fixed particle size of kaolin and ball clay.

4. The samples contain suitable compositions of silica and alumina which complies with percentage compositions of light weight high temperature insulation bricks.

5. Porous clay materials of very low thermal conductivity can be made and used in production of building materials in the tropical region in order to regulate temperatures in houses.

6. Suitable thermal insulator can be made from a mixture of kaolin and ball clay of particle size 125$154 \mu \mathrm{m}$ mixed with sawdust of particle size of 355 $425 \mu \mathrm{m}$. This combination was characterized by the lowest value of thermal conductivity of $0.1579 \mathrm{Wm}^{-}$ ${ }^{1} \mathrm{~K}^{-1}$.

\section{ACKNOWLEDGEMENTS}

The author would like to thank the supervisors at Kyambogo University for their guidance and support during the course of the study and research. Further thanks go to the Management and staff of Uganda Industrial Research Institute, UIRI (Department of Ceramics) for availing me their labs and equipment to be used for the research, and the department of Physics Makerere University. In a special way I wish to appreciate the financial support and courage that I received from my dear wife Ms Nanyama Christine. The support I got from my brother Dr. Mayeku Robert and his wife Mrs. Kate Mayeku, I'm very grateful.

\section{REFERENCES}

[1] Abiriga, F., \& Obwoya, S.K., (2014), Water Purification by Double Filtration Using ceramic Filters, Environment and Natural Resources; Vol. 4 No. 2. ISSN 1927-0488 E-ISSN 1927-0496., pp. 92101.
[2] Ayugi, Gertrude., E. J. K. Banda., Florence Mutonyi D'ujanga., (2011), Thermal properties of selected materials for thermal insulation available in Uganda, a dissertation submitted to the directorate of research and graduate training, Makerere University

[3] Benjamin Iyenagba., and Ogo Emmanuel., (2006), Property Optimization of Kaolin - Rice Husk Insulating Fire - Bricks, Leonardo Electronic Journal of Practices and Technologies ISSN 15831078, p. 167-178.

[4] Bureau of Energy Efficiency, (2005), Energy Efficiency in Thermal Utilities, Ministry of Power, India, Energy Efficiency Guide for Industry in Asia - www.energyefficiencyasia.org @UNEP 2006.

[5] Hanifi Binici., Orhan Aksogan., Mehmet Nuri Bodur., (2007), Thermal insulation and mechanical properties of fibre reinforced mud bricks as wall materials, construction and building materials, Volume 21, Issue 4, pp. 901-906.

[6] Kadir A. A., A. Mohajerani., F. Roddick., and J. Buck-eridge., (2010), Density, Strength, Thermal Conductivity and Leachate Characteristics of LightWeight Fired Clay Bricks Incorporating Cigarette Butts, International Journal of Civil and Environmental Engineering, Vol. 2, No. 4, pp. 10351040.

[7] Katherine, L.C., \& Laurine, E.F. (2002). Implementation of an appropriate house-hold water purification system in Tourou, Cameroon, Retrieved November 17, 2010 from http://www.sys.viginia.edu

[8] Ling W., Gu A. J., Liang G. Z., Yuan L. (2010), New composites with high thermal conductivity and low dielectric constant for microelectronic packaging. Polymer Composites, 31, 307-313 (2010). DOI: 10.1002/pc.20805.

[9] Olufemi Aramide., (2012), Journal of minerals and materials characterization and engineering. Published Online October 2012, (http://www.SciRP.org/journal/jmmce).

[10] Saiah R, B. Perrin., and L. Rigal., (2010), Improvement of thermal properties of fired clays by introduction of vegetable matter, Journal of building physics, 34(2), , 124-142.

[11] Viruthagiri, G., Sri Nithya Nareshananda., and N. Shanmugam., (2013), Analysis of insulating fire bricks from mixtures of clays with sawdust addition, Indian journal of applied research (Physics), Volume: 3 Issue: 6 .ISSN - 2249-555X.

[12] Zhang, S.X.Y., Ma,Y.M., (2011), The effects of particle size and content on the thermal conductivity and mechanical properties of $\mathrm{Al}_{2} \mathrm{O}_{3} /$ high density polyethylene (HDPE) composites.eXPRESS Polymer Letters Vol.5, No.7 581-590 DOI:10.3144/expresspolymlett.57. 